\begin{tabular}{l|l} 
REVISTA & $\begin{array}{l}\text { Revista Educación } \\
\text { ISSN: 0379-7082 } \\
\text { ISSN: 2215-2644 } \\
\text { revedu@gmail.com } \\
\text { Universidad de Costa Rica } \\
\text { Costa Rica }\end{array}$
\end{tabular}

\title{
Aproximación metafórica del ejercicio de la función directiva
}

Rodríguez Revelo, Elsy

Aproximación metafórica del ejercicio de la función directiva

Revista Educación, vol. 44, núm. 2, 2020

Universidad de Costa Rica, Costa Rica

Disponible en: http://www.redalyc.org/articulo.oa?id=44062184030

DOI: https://doi.org/10.15517/revedu.v44i2.39758

Esta obra está bajo una Licencia Creative Commons Atribución-NoComercial-SinDerivar 3.0 Internacional. 


\title{
Aproximación metafórica del ejercicio de la función directiva
}

\author{
A Metaphorical Approach to the Execution of Management Roles \\ Elsy Rodriguez Revelo \\ Universidad de Guayaquil, Ecuador \\ DOI: https://doi.org/10.15517/revedu.v44i2.39758 \\ Redalyc: http://www.redalyc.org/articulo.oa?id=44062184030
}

rev_49@hotmail.com

(DD http://orcid.org/0000-0003-4486-0785

Recepción: 31 Enero 2020

Aprobación: 21 Junio 2020

\section{ReSUMEN:}

Las metáforas permiten describir prácticas implícitas de la función directiva en contextos complejos no contemplados en la normativa y políticas educativas como es el caso de España. Es así que, el propósito de esta investigación fue develar roles que desempeñan los directores de centros educativos en relación con las funciones que ejercen los directivos en ciudades como Zaragoza (España). Para ello, se utilizó un enfoque cualitativo, aplicando el diseño de caso múltiple, apoyados en técnicas como la observación no participante, análisis documental, entrevistas a profundidad y grupos de discusión. Entre los resultados emergen roles que asumen las personas directoras para responder a las necesidades puntuales del estudiantado, influyendo de manera directa e indirecta en la forma de ejercer la función directiva en una institución educativa. El estudio se desarrolló sin pretender que sea representativo de los diversos centros escolares situados en contextos semejantes a los tres casos analizados. Sin embargo, el comprender el entramado que atañe el ejercicio de la función directiva permite que, a criterio del lector puedan extrapolarse a otras realidades casi similares, pues la esencia no es generalizar sino describir lo que ocurre en el escenario, entenderlo, comprenderlo para finalmente descubrirlo. Por tanto, es una invitación a la reflexión sobre las implicaciones que atañe el ejercer la función en contextos socialmente adversos.

Palabras clave: Metáforas, Director, Contexto, Práctica, Roles.

\section{ABSTRACT:}

Metaphors allow us to describe implicit practices associated with management roles when having to contend with complex contexts not addressed by educational regulations and policies, as identified in Spain. Thus, this study endeavors to uncover the roles of school principals in the city of Zaragoza, Spain. This is a qualitative study with a multiple-case design backed by techniques such as non-participatory observation, document analysis, in-depth interviews and discussion groups. The results reveal the different roles of principals when responding to specific student needs, which also directly and indirectly impacts how the schools is managed. The study does not claim to be representative of similar contexts for the three school cases that were analyzed. Nevertheless, it is important to understand the management function framework in order to extrapolate it to similar scenarios. The spirit of this study is to describe and understand the current scenario to, ultimately be able to uncover it. Thus, the approach must be that of reflecting on the repercussions when executing management functions amidst similar contexts of social adversity. KEYWORDS: Metaphors, Management, Contexts, Practices, Roles.

\section{INTRODUCCIÓN}

Desde el punto de vista de la publicación del Suplemento Futuro del año 1993 las metáforas como explicación de una realidad, se utilizan en procesos cognitivos perceptuales; como unidad elemental trata de explicar el comportamiento de un fenómeno que, al adentrarse, como señala Borges citado por Cavallín (2008) trasladan sensaciones, tratan de explicar los hechos, facilitando la comprensión para otros, aporta que los hombres creen un universo en la mente. De ahí que, cada alegoría tiene sentido, porque existe una interacción entre los diferentes discursos (Vázquez, 2007a). En este sentido, las alegorías se presentan como un modelo que figura lo conceptual y una imagen de lo real; a criterio de Eagleton (1983) es introducir nuevos matices para comprender de otra manera la realidad. 
Las entidades educativas, tienen un entramado de relaciones, que no se explican fácilmente haciendo uso de las teorías clásicas; los sujetos se asocian de maneras no formales, poco visibles en los esquemas organizacionales, pretendiendo buscar una descripción a través de metáforas, así los centros educativos no están formados por individuos aislados. Ellos tejen redes (formales e informales) que son organizaciones de interacciones. Al respecto las formales se visualizan fácilmente en un organigrama jerárquico que burocratizan los procesos, mientras que, las informales emergen por factores (endógenos y exógenos) siendo flexibles y adaptables al contexto.

\section{Antecedentes de estudio}

Cantón y Arias (2010) señalan algunas alusiones que contextualizaban con exactitud la tarea directiva, en cuanto a los modos de acceso dibujándolos como: mesiánicos (salvadores, víctimas y necesarios), pues rechazan el liderazgo, porque la asunción del cargo fue por necesidad; a su vez se retractan como masoquistas y víctimas. Luego están los gestores ilustrados (burócratas) legalistas, con ausencia de liderazgo.

En tercer lugar, están los vocacionales con liderazgo y actitud de servicio, caracterizados por ser apasionados por el trabajo, alcanzando buenos resultados y mejor clima organizacional. Igualmente, al considerar los factores que motivan a los directores al cargo, ilustran las siguientes metáforas: Los imprescindibles (alto concepto de sí mismo), paternalistas, describiendo los perfiles como aquellos que usan la zanahoria y el garrote (recompensas y castigos). También detalla a los directores condicionales (circunstancias para aceptar el cargo), la tarea directiva es más de subsistencia, se mueven entre la incertidumbre, la rutinización y los transformacionales, más por vocación y deseo de cambio.

En un trabajo de Lorenzo (2005) se expone algunas metáforas para describir el liderazgo de los directores a manera de caleidoscopio, en el que cada persona construye una figura de líder, con base a lo que ve: arquitecto, catalizador, defensor del grupo, profeta o poeta. Además, de diseñador, mayordomo o maestro, al igual de transaccional. El autor, recoge otras que se describen a continuación:

- Centrado en principios: conducta que guían al líder

- Intuitivo: líder humanista

- Transcultural: organizaciones culturalmente diversas

- Global: líder que desarrolla habilidades globales

- Líder como entrenador: facilitador de grupo

- Visionario: líder con visión de centro

Tampoco se puede obviar otras metáforas como las utilizadas por Goleman (2002) liderazgo resonante, conocida como liderazgo emocional y el líder clarividente, por su visión de futuro, entre otras. En palabras de Lorenzo (2005) "todas llaman la atención sobre el modo de ejercer la función, el cómo se ejecuta o debe desarrollarse" (p. 374). Con ello, se busca identificar con mayor aproximación lo que hace el director y el cómo lo ejecuta, con detalles que en ocasiones la teoría no logra hacerlo.

Para Domínguez (2010) el líder es como el carpintero, porque ve en las personas las cualidades y virtudes. Igualmente, Díaz, Alfaro, Calderón y Álvarez (2010) señalan al director como la cabeza de la organización, siendo la figura principal, responsable del centro educativo y la dirección como una muralla, que al profesorado no le permite avanzar.

De ahí que, uno de los objetivos de esta investigación fue analizar las prácticas de la función directiva en centros educativos de difícil desempeño o que se encuentran en contextos inciertos, o entornos socialmente complejos e inferir, a través del diálogo con directivos, docentes, estudiantes y las familias metáforas que conceptualizan otras actividades que desarrollan los directores, además de las contempladas en la normativa. 
El estudio se hizo en el año 2015 y finalizó con la sustentación de la tesis doctoral, en febrero del año 2017. No es la primera publicación que se hace de los resultados, que abordaron los perfiles directivos y de liderazgo, construidos a partir de las voces de los actores educativos. Esta publicación, parcial, vio la luz en un artículo de Rodríguez (2018) en la revista Perspectiva Educacional (Chile).

Tal como menciona Vázquez (2007b) los estudios en Iberoamérica en relación con la dirección escolar, que toman como referencia las metáforas para describir la realidad de la práctica de la función directiva son escasos, de ahí la importancia de esta investigación.

En conclusión, el director de un centro educativo se enfrenta a una multiplicidad de tareas que son difíciles de abarcarlas totalmente en un manual o normativa legal. Por tanto, muchas de ellas quedaran en la zona oscura, al no tener una etiqueta que las identifique y buscar conceptualizarlas aporta con mayor detalle a transparentar el perfil y las funciones de quienes cumplen con esta tarea.

\section{Hacia una definición de los símbolos metafóricos}

"Las metáforas se utilizan como un recurso de sistematización de teorías y conceptos; es decir, permiten describir con mayor precisión una realidad vivida por los sujetos, difícil de explicar con aportes teóricos y prácticos según la imagen o metáfora" (Antonorsi, 2017, p. 4). Entonces, a través de ella se busca interpretar el quehacer educativo de los actores, en particular, de quién asume la función directiva, los múltiples roles que a simple vista son poco explicables teóricamente.

Las metáforas son una forma de hablar sobre una cosa describiendo otras, por lo que, se piensa con los sentidos y la imaginación; considerándolas ni verdadera ni falsas. No obstante, se enfatiza que más que ciencia las metáforas son arte, pues se razona en imágenes, permitiendo sentir las cosas directamente, dando a las palabras una forma de ir más allá del propio significado. Son las manijas en las puertas de lo imaginado; es decir cada puerta conduce a una casa nueva y algún mundo nuevo, que solo esa manija puede abrir. Lo increíble se fundamenta que, haciendo una manija se puede hacer un mundo. (Hirshfield, 2014, p. 2)

De acuerdo con Alcaide (2009), entre las alegorías conocidas están las del centro como máquina u organismo, idea postulada inicialmente por Morgan en los años 80, cuya visión es ortodoxa, propia de procesos tayloristas de escuelas del siglo XIX, al igual que la concepción de burocracia de Weber. En este sentido, las ideas de Antonorsi (2017) dejan claro que la complejidad de las organizaciones exige observarse en todas las facetas, pues no son ni cerebros, ni organismos.

Las organizaciones son más que simples procesos tayloristas; en consecuencia, las metáforas constituyen una herramienta que devela el significado de ciertas prácticas poco visibles, por parte de los actores educativos. Entonces, es un mecanismo posible de acercarse al entramado que se teje detrás de la micropolítica de los centros educativos y función directiva.

Dentro de este marco, la metáfora coadyuva a la construcción de la realidad: social, cultural y política, de la dirección escolar, la práctica, dinámica diaria; crear y recrear el ejercicio diario de la función directiva, no basta con el lenguaje literal, porque un directivo -pieza clave para el buen funcionamiento de la institución educativa- es una figura que se le exige respuestas oportunas desde todos los ángulos: familiares, estudiantiles, docentes, de la administración educativa, cuerpos colegiados y no colegiados, que debe rendir cuentas, evidenciadas a través de los resultados de aprendizaje y la deserción escolar.

De ahí que Bunk (1994) y Tejada (1999) manifiestan que el director escolar no solo tiene competencias de líder, dotes de administración, entre otras, sino que debe ser un motivador de las familias, mediador, facilitador de conocimientos, recursos, tener estrategias ingeniosas para crear, y llevar a la práctica proyectos. Por consiguiente, como afirma Bolívar (2018) la "dirección escolar constituye un sector estratégico que cuenta entre sus potencialidades la mejora educativa” (p. 4). Por ello, al director se le relaciona con la calidad o el fracaso del centro, por la capacidad para liderar un proyecto conjunto de acciones que atiendan la 
transformación de la escuela, por la influencia silenciosa, persistente y beneficiosa que aporte al crecimiento de la comunidad educativa.

Las metáforas permiten nombrar las tareas que desempeña un directivo tras bastidores, a su vez, analizar las interrelaciones entre las funciones, los roles, la estructura y la cultura organizativa. Según, Gago y San Fabián (1993), Gairín (1995), Martínez (2003), Lorenzo (2011) y Santos (2015) las funciones que suelen desempeñar los directores de centros educativos, entre otras son: pedagógicas, supervisión y control, investigadora, construcción cultural, toma de decisiones, responsable de la buena convivencia del centro, función representacional. Además, desarrollan tareas de gestión económica, de personal, organizador de formación, gestoras de evaluación, gestoras de prevención de riesgos laborales.

Sin embargo, los directores asumen otras funciones que exige profesionalismo, formación inicial y permanente, puesto que son amplias las áreas de responsabilidad, las cuales emergen según la complejidad del contexto para responder a cuestiones desafiantes y a la problemática socioeconómica del mayor grupo de familias que pueblan centros ubicados en entornos adversos. Dentro de este marco, no se puede hablar de perfiles, como tampoco estilos de liderazgos puros de dirección escolar.

Por ello, para dibujar y dotar de especificidad se recurre a metáforas que declaran y delatan, en gran medida los modelos de pensamiento que no lograrían alcanzar la luz. Según Vázquez (2007b) “en los registros educativos fácilmente se encuentra toda una serie de imágenes que entran a formar parte del lenguaje cotidiano. Se utilizan con la misma naturalidad que cuando se recurre a otras palabras que no evocan otra realidad diferente" (p. 140).

En conclusión, a partir del siguiente estudio se ampliará estas particularidades implícitas en la tarea directiva para transparentar e ir buscando fortalecer el perfil de quienes ejercen la rectoría de los centros de enseñanza.

\section{Materiales Y MÉtodos}

La investigación tuvo un enfoque cualitativo (Guba, 1981) pues permite aclarar de manera minuciosa la vida que existe detrás de cada centro. No todas las personas que forman parte de este ven, leen y comprenden la realidad de la misma manera. Por ello la variedad de instrumentos técnicos que brinda la investigación cualitativa permitió obtener una visión uniforme de los centros, tras un riguroso proceso de análisis. Es decir, en una investigación cualitativa el investigador se acerca al mundo de "ahí afuera” (Flick, 2014, p. 12), alejados de laboratorios, propio de las ciencias médicas, para analizar los problemas sociales e interpretarlos. Por tanto, no se formularon hipótesis, para construir conceptos que se mejoran en el proceso de investigación.

Asimismo, se optó por un diseño de estudio de caso múltiple, ya que se abordan más de dos casos. En palabras de Bogdan y Biklen (2003) "cuando los investigadores estudian dos o más sujetos, ambientes o depositarios de datos, están haciendo usualmente lo que se llama estudio de casos múltiples” (p. 62). De ahí que, de cara a este trabajo, se asumió como un método de acción e indagación cuyo interés fue comprender una realidad social y educativa; como diseño de estudio y método se convirtió en un puente entre la teoría y la vida cotidiana de quien ejerce la función directiva en los centros escolares, tomando en cuenta las facetas en un entorno controvertido (Vázquez, 2011).

La población de estudio, la constituyó tres centros educativos públicos de Educación Infantil- Primaria de la ciudad de Zaragoza (España) identificados como centros de difícil desempeño. Todos ellos están en contextos socialmente complejos, considerando las particularidades de cada uno, sin generalización se eligieron de manera intencional, porque a través de la Administración Educativa de la ciudad apoyaron a la identificación de estos, por los bajos resultados académicos y para otros guettos educativos (familias inmigrantes y gitanas, poco atractivos para la población zaragozana) cuyos actores educativos fueron parte del estudio. Debido a exigencias en el proceso de negociación para el acceso al campo se respetó el anonimato 
de los centros participantes, que de ahora en adelante se identificaran como Caso A (CA), Caso B (CB) y Caso C (CC).

Las técnicas de recogida de la información vienen determinadas por el método seguido en el desarrollo de la investigación. La perspectiva que prima en este tipo de estudios es la del actor (Sabirón, 2006) o de los integrantes del núcleo investigado, de allí, la información se recogió a partir de las siguientes técnicas: entrevista en profundidad y grupos de discusión (Barbour, 2013); con ello, la población participante fueron familias, el alumnado, el profesorado y el equipo directivo. El levantamiento de datos se hizo durante el ciclo escolar abril 2015 y finalizó en junio del año 2016.

El proceso de investigación siguió los postulados de Nieto (2012) y Tojar (2012) quienes señalan los pasos a seguir en dos momentos de la investigación: de campo y de análisis:

1.- Negociación: el proceso de acceso parte con el acercamiento a la administración educativa, solicitando la facilidad de visitar tres centros educativos ubicados en contextos de alta complejidad social (migración, familias numerosas, bajo resultados académicos, entre otros). A los pocos días se inicia el diálogo con los directores de cada entidad, comentando a una conversó con cada uno de los colectivos (familias, el alumnado, el profesorado y el personal de servicio, entre otros.);se pretendía que la participación sea voluntaria, pues el forzar se aboca a situaciones incómodas y restan veracidad a la información primaria. Algunas personas manifestaron su negativa, señalando no confiaren la preservación del anonimato.

2.- Trabajo de campo: pistas de indagación, recopilación de datos con las técnicas antes descritas.

3.- Análisis de datos y categoría de significados: para ello se utilizó el software informático Nvivo y $o$ transcribe.

4.- Resultados: se presentaron como categorías que crean un universo completo con espacio propio, sentido y relevancia.

El contexto donde se desarrolló el trabajo de campo y se recogió la muestra fue tres centros educativos públicos de la ciudad de Zaragoza (España). El Centro educativo Caso A (CA) ubicado en un barrio periférico de Zaragoza, forma parte de lo denominado Término de Mirabueno resultado de la parcelación de fincas rurales sobre las que se levantaron las primeras viviendas. La población, en su mayoría son familias jóvenes con niveles formativos bajos, población anciana y en los últimos años se integran a las familias inmigrantes y hogares monoparentales, formados por madres solteras.

El promedio de hijos por familia es de tres. Por lo tanto, la población escolar en este colegio es superior a la media de la ciudad (Milenium 3,2010). A la fecha de esta investigación el centro tenía una matrícula aproximada de 200 estudiantes, el cuerpo docente llega por Comisión de servicio; de las familias de la institución educativa el $61 \%$ corresponde a la etnia gitana, 34\% inmigrantes y $5 \%$ otros grupos. De acuerdo, al análisis hecho por Milenium 3 (2010) los centros ubicados en estos sectores son verdaderos guetos socioeducativo. A todo se destaca que la directora, al igual que el equipo directivo tienen dos años en funciones.

Centro Educativo Caso B (CB); entidad ubicada en una de las zonas tradicionales de Zaragoza (España), conocida como Zona del Casco Antiguo, el Gancho, actualmente San Pablo. Entre calles estrechas con poca ventilación y luz solar, las viviendas son de bajo coste por abandono en el mantenimiento, en ocasiones habitadas por familias ilegalmente, varias de ellas, comparten una sola casa, ahondando la situación de miseria (Proyecto Educativo de Centro, 2015).

La institución educativa funciona en un edificio construido en el siglo XVI, antiguo palacio de los Duques de Villahermosa. Acoge a estudiantes multiculturales: gitanos portugueses, magrebíes (argelinos y marroquíes) subsaharianos, chinos, sudamericanos, entre otros. En el ciclo Escolar 2015-2016 tenía un aproximado de 150 escolares, con profesorado en Comisión de Servicio.

Centro Educativo Caso C (CC), ubicado en una zona de regeneración urbana de la ciudad, conocida como el Paseo Fluvial, remodelado y modernizado en el año 2008. Allí se sitúan viviendas antiguas habitadas por familias con bajos ingresos económicos (gitanos e inmigrantes). A diferencia de los casos descritos, la 
población con mejores ingresos económicos y nivel cultural no se autoexcluye; el estudiantado tiende a crecer y volverse atractivo para las familias modernas, debido a los programas educativos como el Programa British Council. La directora cuenta con 30 años de servicio docente y 10 años ejerciendo la dirección de centros educativos.

Se desarrolló un instrumento como pauta general y básica para las entrevistas y grupos de discusión. Entre los temas abordados destacan: criterios personales para asumir la dirección del centro, descripción del contexto del centro educativo, limitantes para ejercer la función directiva, tareas que se desarrollan enmarcadas a la normativa y cuáles se ejercen como respuesta a las necesidades de la entidad, las que se adaptan según las opiniones de los participantes.

Las intervenciones fueron recogidas, con autorización de los informantes, en una grabadora y analizadas de manera individual, pero buscando coincidencias y discrepancias en el diálogo de los informantes. En total se organizaron dos grupos de discusión en cada centro y por actores educativos, docente, equipo directivo y familia. En el caso de las entrevistas 10 (CA), 14 (CB); y 6 Caso (CC). Cada entrevista tuvo una duración mínima de 60 minutos, aplicando las siguientes identificaciones: entrevista en profundidad EP, grupos de discusión GD, en el caso de los actores que guardan relación directa e indirecta con el centro educativo se tiene, docentes (D), director (DIR), conserje (C), padres de familias (PF), estudiantes (E), jefe de estudio (JE), secretaria $(S)$.

Se utilizó la técnica de la triangulación entre informantes, en la búsqueda de coincidencia y discrepancias entre los discursos. Extrayendo categorías lo suficientemente significativas, claras, mutuamente excluyentes, descriptoras del universo completo, con sentido y relevancia. Las metáforas que se exponen no solo responden al habla común de los participantes del estudio, también a la interpretación que la investigadora hace de la información proporcionada por las personas.

Tras el estudio de la práctica de la función directiva (Rodríguez, 2018) no solo se identificaron las tareas y perfiles expuestos: perfil transformador con liderazgo pedagógico y compartido (Caso A), técnico racional (Caso B) y directivo consultivo, también se reconoce como político, más allá de lo exigido por la reglamentación; el director escolar en contextos complejos ejecuta una serie de tareas, identificadas en la voz de los entrevistados con metáforas. Las que hacen referencia los resultados, pues describen nuevos rasgos que deben agregarse, a los ya descritos, para definir contextualmente la figura de un director en ciertos entornos; y que marquen diferencias entre un sujeto y otro, responsable de esta función. En los tres casos estudiados reaparece la metáfora del bombero.

1. Negociación: el proceso de acceso parte con el acercamiento a la administración educativa, solicitando la facilidad de visitar tres centros educativos ubicados en contextos de alta complejidad social (migración, familias numerosas, bajo resultados académicos, entre otros). A los pocos días se inicia el diálogo con los directores de cada entidad, comentando a una conversó con cada uno de los colectivos (familias, el alumnado, el profesorado y el personal de servicio, entre otros.);se pretendía que la participación sea voluntaria, pues el forzar se aboca a situaciones incómodas y restan veracidad a la información primaria. Algunas personas manifestaron su negativa, señalando no confiaren la preservación del anonimato.

2. Trabajo de campo: pistas de indagación, recopilación de datos con las técnicas antes descritas.

3. Análisis de datos y categoría de significados: para ello se utilizó el software informático Nvivo y o transcribe.

4. Resultados: se presentaron como categorías que crean un universo completo con espacio propio, sentido y relevancia.

El contexto donde se desarrolló el trabajo de campo y se recogió la muestra fue tres centros educativos públicos de la ciudad de Zaragoza (España). El Centro educativo Caso A (CA) ubicado en un barrio periférico de Zaragoza, forma parte de lo denominado Término de Mirabueno resultado de la parcelación 
de fincas rurales sobre las que se levantaron las primeras viviendas. La población, en su mayoría son familias jóvenes con niveles formativos bajos, población anciana y en los últimos años se integran a las familias inmigrantes y hogares monoparentales, formados por madres solteras.

El promedio de hijos por familia es de tres. Por lo tanto, la población escolar en este colegio es superior a la media de la ciudad (Milenium 3, 2010). A la fecha de esta investigación el centro tenía una matrícula aproximada de 200 estudiantes, el cuerpo docente llega por Comisión de servicio; de las familias de la institución educativa el $61 \%$ corresponde a la etnia gitana, $34 \%$ inmigrantes y $5 \%$ otros grupos. De acuerdo, al análisis hecho por Milenium 3 (2010) los centros ubicados en estos sectores son verdaderos guetos socioeducativo. A todo se destaca que la directora, al igual que el equipo directivo tienen dos años en funciones.

Centro Educativo Caso B (CB); entidad ubicada en una de las zonas tradicionales de Zaragoza (España), conocida como Zona del Casco Antiguo, el Gancho, actualmente San Pablo. Entre calles estrechas con poca ventilación y luz solar, las viviendas son de bajo coste por abandono en el mantenimiento, en ocasiones habitadas por familias ilegalmente, varias de ellas, comparten una sola casa, ahondando la situación de miseria (Proyecto Educativo de Centro, 2015).

La institución educativa funciona en un edificio construido en el siglo XVI, antiguo palacio de los Duques de Villahermosa. Acoge a estudiantes multiculturales: gitanos portugueses, magrebíes (argelinos y marroquíes) subsaharianos, chinos, sudamericanos, entre otros. En el ciclo Escolar 2015-2016 tenía un aproximado de 150 escolares, con profesorado en Comisión de Servicio.

Centro Educativo Caso C (CC), ubicado en una zona de regeneración urbana de la ciudad, conocida como el Paseo Fluvial, remodelado y modernizado en el año 2008. Allí se sitúan viviendas antiguas habitadas por familias con bajos ingresos económicos (gitanos e inmigrantes). A diferencia de los casos descritos, la población con mejores ingresos económicos y nivel cultural no se autoexcluye; el estudiantado tiende a crecer y volverse atractivo para las familias modernas, debido a los programas educativos como el Programa British Council. La directora cuenta con 30 años de servicio docente y 10 años ejerciendo la dirección de centros educativos.

Se desarrolló un instrumento como pauta general y básica para las entrevistas y grupos de discusión. Entre los temas abordados destacan: criterios personales para asumir la dirección del centro, descripción del contexto del centro educativo, limitantes para ejercer la función directiva, tareas que se desarrollan enmarcadas a la normativa y cuáles se ejercen como respuesta a las necesidades de la entidad, las que se adaptan según las opiniones de los participantes.

Las intervenciones fueron recogidas, con autorización de los informantes, en una grabadora y analizadas de manera individual, pero buscando coincidencias y discrepancias en el diálogo de los informantes. En total se organizaron dos grupos de discusión en cada centro y por actores educativos, docente, equipo directivo y familia. En el caso de las entrevistas 10 (CA), 14 (CB); y 6 Caso (CC). Cada entrevista tuvo una duración mínima de 60 minutos, aplicando las siguientes identificaciones: entrevista en profundidad EP, grupos de discusión GD, en el caso de los actores que guardan relación directa e indirecta con el centro educativo se tiene, docentes (D), director (DIR), conserje (C), padres de familias (PF), estudiantes (E), jefe de estudio (JE), secretaria $(S)$.

Se utilizó la técnica de la triangulación entre informantes, en la búsqueda de coincidencia y discrepancias entre los discursos. Extrayendo categorías lo suficientemente significativas, claras, mutuamente excluyentes, descriptoras del universo completo, con sentido y relevancia. Las metáforas que se exponen no solo responden al habla común de los participantes del estudio, también a la interpretación que la investigadora hace de la información proporcionada por las personas.

Tras el estudio de la práctica de la función directiva (Rodríguez, 2018) no solo se identificaron las tareas y perfiles expuestos: perfil transformador con liderazgo pedagógico y compartido (Caso A), técnico racional (Caso B) y directivo consultivo, también se reconoce como político, más allá de lo exigido por la 
reglamentación; el director escolar en contextos complejos ejecuta una serie de tareas, identificadas en la voz de los entrevistados con metáforas. Las que hacen referencia los resultados, pues describen nuevos rasgos que deben agregarse, a los ya descritos, para definir contextualmente la figura de un director en ciertos entornos; y que marquen diferencias entre un sujeto y otro, responsable de esta función. En los tres casos estudiados reaparece la metáfora del bombero.

\section{El director bombero y/o apagafuego.}

El director es considerado en los centros educativos como el apagafuego, apaciguador del problema; los actores de la institución ven al equipo directivo como el cuerpo de bomberos. En los discursos el personal docente suele manifestar que los directivos brindan un servicio de urgencia que reacciona frente a cualquier eventualidad a causa de los conflictos; situación que ocupa la mayor parte de la jornada de trabajo. En este sentido, uno de los hándicaps de los centros ubicados en contextos complejos, son los conflictos que batalla el director a diario.

Valga el caso, la acción de los directores se da sobre el siguiente contexto "Él tiene que apagar muchos fuegos [...] él tiene que apagar muchos fuegos constantemente [...] problemáticas muchas [...] nuestro director apaga fuegos, no tenemos ni tiempo para hablar, lo importante es atajar el conflicto" (EP-D1-CB) (Rodríguez, comunicación personal, 19 de diciembre de 2019). De acuerdo a lo expuesto, se observa que los directores luchan con varias situaciones emergentes considerándose como un apagafuegos de los acontecimientos que suceden en el diario vivir del entorno académico.

El personal no docente reflexiona sobre la magnitud de los problemas con la siguiente frase "Mientras en algunos lugares son colillas aquí encienden la cerilla completa (EP-C-CA); como director nos toca apagar fuego en todo momento (EP-DIR-CC); -Yo creo que el director todavía se dedica a apagar fuegos dentro de las instituciones-" (EP-DIR-CC) (Rodríguez, comunicación personal, 19 de diciembre, 2019).

El director del caso B señala que la dedicación, casi, exclusiva a la resolución de conflictos impide una reflexión sobre la propia práctica y atender a las rutas o protocolos exigidos. No obstante, aunque el directivo infiere que los conflictos son el indicativo que algo se hace mal. Desde la reacción a la innovación institucional, en ocasiones, se considera que las familias, además del estudiantado son parte más del cambio que de la solución.

A lo anterior se suma, el descontento de docentes y directivos obligados a apoderarse roles, para los cuales no fueron formados y no son considerados en la enseñanza, eludiendo su compromiso, más que educativo, social, de ahí que los describen como balsa de aceite (EP-D-CB); su aparición es como ciclos de vida, en el cual los problemas que tiene el centro no se apagan nunca, simplemente bajan de intensidad y pasa por etapas: nace, crece y se reproduce.

Según la gestión del director, los inconvenientes pueden morir, pero en la mayoría de los casos se transforman, haciendo que permanezcan latentes en la cotidianidad del centro, tanto que son reconocidos por la autoridad, como conflictos sin resolver. Se los identifica comoflecos (EP-D-CB), justificando que la no resolución de los conflictos, se da por disconformidad de las partes involucradas en las decisiones tomadas o porque la solución no estaba en sus manos.

Hay conflictos latentes en todos los ámbitos [...] ojalá fuera todo como una segadora que allá por donde pasa lo deja todo liso, vuelve la vista atrás y ha quedado todo perfecto. No es así van quedando flecos, haces una actuación y alguien se queda disconforme, o haces una actuación y nadie se queda conforme del todo, o alguien se queja de someter su queja y no se la resuelven como él o ella estimaría oportuno [...] Entonces esas son cosas que van formando una amalgama de cosas pendientes (EP-D-CA) (Rodríguez, comunicación personal, 19 de diciembre de 2019). 


\section{Director que vigila y controla}

A través de la vigilancia y el control procura mantener la disciplina, toma decisiones carentes de sentido educativo y más punitivo, haciendo uso de la autoridad legítima, utiliza el castigo como método rehabilitador. Sin embargo, tras las entrevistas aplicadas se infiere una práctica sancionadora, ejercida por el director que genera una dinámica de bucle, en la cual la acción represiva resuelve un conflicto; y a la vez crea otro. Adicional, de preventivo, es de reformatorio (castigos como método rehabilitador y recurso que legítima su poder). Práctica que se convierte en un bucle; la acción represiva resuelve un conflicto y a la vez crea otro.

A esto se suma la tarea de controlador por la complejidad e imprevisibilidad de los problemas presentes en el contexto aula. De ahí que, se reflexiona que el director es un pulpo (muchas manos que abarcar todas las situaciones que se presentan día diario). Lechuza (visión binocular), porque requiere tener a la vista un panorama amplio de lo que ocurre en cada dependencia del centro educativo, con estudiantes y docentes que dibujan a un director metamorfosis capaz de cambiar según las necesidades del centro educativo.

\section{Director preventivo y mediación}

Tanto en el caso A, como en el B se evidencia otro modo de trabajar el conflicto a través de programas de prevención. Por ejemplo, talleres estudiantes en relación con el conflicto y cómo evitarlo, además prácticas como el mindfulness (respiración consciente); cuando los conflictos aparecen se toma en cuenta la vía de la mediación, que se construye sobre la base de la escucha activa, quien ejerce la función directiva considera que el diálogo permite conocer las necesidades de otra persona, estar al tanto de las causas que conducen a transgredirla, para ello la reflexión, el conocimiento de las emociones y el reconocimiento de los errores $\sin$ justificar, mejora sustancialmente los procesos punitivos.

Nosotros trabajamos mucho en la línea de la prevención; lo que intentamos es prevenir, para evitar la aparición de conflictos y en esa línea está el alumnado ayudante mediador [...] Aplicar medidas correctoras siempre será el último recurso (EP-DIR-

CA) (Rodríguez, comunicación personal, 19 de diciembre de 2019).

En el caso C, si bien se ejerce el control y la vigilancia, ya condicionada hacia el estudiantado que está etiquetado como problemático, el proceso permite marcar directrices con el grupo en particular y ejercen prácticas ritualistas, también presentes en los casos $\mathrm{A}$ y $\mathrm{B}$, que bien se podrían describir como el trazado de rutinas pautadas y controladas (norma); en donde el director vigila el cumplimiento (llegada puntual, formación, pasar a los salones, no sentarse mientras se da indicaciones...).

A la directora la tienes en la puerta a las nueve, controlando a los problemáticos. A este grupo, los tiene controlados (EP-FCC) (Rodríguez, comunicación personal, 19 de diciembre de 2019).

No obstante, quien ejerce la dirección en este centro, acude a la mediación, siguiendo los pasos descritos en el caso anterior: escuchar, dialogar y trabajar en la prevención de los conflictos. "el conflicto hay que prevenirlo [...] hay que intentar resolverlos utilizando la mediación [...] agotando todos los caminos antes de llegar a una solución más traumática" (EP-DIR-CC) (Rodríguez, comunicación personal, 19 de diciembre de 2019).

Personal docente con trayectoria y experiencia en otros centros manifiesta que es el único establecimiento donde ha laborado, que utiliza protocolos para solucionar problemas con el diálogo y la mediación. En virtud de esto, el despacho del director, visto en ocasiones como un espacio inquisitorial, lo describen con la metáfora del diván y para el director utilizan la metáfora del terapeuta; ellos comentan los problemas y los acompañan a reflexionar sobre estos. Es una práctica reconocida por estudiantes y familias; pero los dos últimos grupos lo describen como el psicoanalista. 
Es el único cole que he visto que siempre hay un niño en el despacho, pero no castigado, hablando con ellos, o sea reflexionando. Creo que esa labor de relación de diálogo con los padres es importante [...] en otros centros no se llega a ese diálogo [...] es una imposición. Te vas al despacho, pero de allí no te mueves [...] pero esa comunicación [...] eso lo tienen todos los días en el despacho, es como un diván y la directora su terapeuta (GP-D-CA) (Rodríguez, comunicación personal, 19 de diciembre de 2019).

[...] Yo puedo contarle un problema, un problema fuerte y sé que me va a ayudar, no la consideramos directora, no, sino como un psicoanalista [...] es una persona que escucha, que la tenemos para todo, para lo que nos haga falta [...] es una persona que se implica mucho, en las familias, en todo (GP-F-CA) (Rodríguez, comunicación personal, 19 de diciembre de 2019).

En el Caso B, los castigos son utilizados como método rehabilitador, que es una práctica en bucle: la acción represiva resuelve un conflicto y a la vez crea otro, sin carácter preventivo. El director es referido por las y los docentes como la persona de los mil ojos en cada parte; y para otros como el sargento muy criticado por estudiantes, en donde la mediación no se evidencia, más bien se reflejan castigos poco educativos: repetir copias, apartarlos de la clase y ponerlos de pie.

800 copias al que se porta mal [...] en educación física, si no traemos el neceser nos manda primero hacer 21 y luego otro día cien [...] Si tienes mala conducta estás expulsado tres días o cuatro días [...] En el colegio hay un estudiante que lo han expulsado tantas veces que hasta ha perdido la cuenta (GD-E-CB) (Rodríguez, comunicación personal, 19 de diciembre de 2019).

El hecho que el director sea estricto te obliga a que algunos estudiantes se cansen de él y acabarán denunciándole; debería ser amable y estricto cuando haga falta [...] los niños demuestran cierto temor hacia el director por su actitud intransigente, tecnócrata, debería ser más acogedor (GP-E-CB) (Rodríguez, comunicación personal, 19 de diciembre de 2019).

Entonces no existe un proceso de mediación y tampoco un perfil mediador, que estudiantado exige:

[...] Si la profesora te enviara donde él (director), sería en plan de diálogo que impulse a reconocer que has cometido una falta y que estás arrepentido y dices lo siento. Pero es todo lo contrario, vas donde él y te pregunta con tono altivo tú que has hecho ahora y te mira con mala caras. Yo como directora lo haría en plan amigo (GP-E-CB) (Rodríguez, comunicación personal, 19 de diciembre de 2019).

Al contrario de lo que significa el despacho de la directora del caso A, en algunas entrevistas se refleja para el alumnado y sus familias llegar a este espacio físico, representa un castigo: “yo siempre los estoy amenazando con el director [...] cuando los amenazo con que los voy a llevar a la dirección, ya va la cosa un poco más suave [...] les nombras dirección y ya se ponen, así como un poco más firme" (EP-C-CB) (Rodríguez, comunicación personal, 19 de diciembre de 2019).

Producto de lo anterior se desarrollan relaciones frías y distantes entre la comunidad educativa, a pesar de que defienden el trato formal que brinda el director, el profesorado menciona explícitamente que el rol de sancionar y menos mediador lo perfila como un director que le falta "habilidades para tratar con las familias: creo que al director le faltan habilidades para tratar con las familias, precisamente por esa rectitud que tiene" (EP-D-CB) (Rodríguez, comunicación personal, 19 de diciembre de 2019).

En los casos $\mathrm{A}$ y $\mathrm{C}$ se identificaron otras metáforas que se detallan a continuación:

\section{Rolmaterno}

Está metáfora se utiliza para describir el rol de madre que ejercen los directivos del centro a causa de ciertas carencias afectivas de muchos estudiantes, pues para un mejor proceso educativo el brindar una estabilidad emocional es una necesidad que el director trata de solventar, pues es un factor que, según ellos, incide en los resultados académicos del alumnado.

Es que hacemos un rol materno constantemente, aquí en este cole no somos maestros, el rol materno lo hacemos constantemente. Desde luego no sustituimos el papel de sus padres [...] somos un referente tan importante como sus padres [...] le transmitimos a ellos una estabilidad emocional que a veces no tienen (EP-DIR-CA) (Rodríguez, comunicación personal, 19 de diciembre de 2019). 
Docentes y personal no docente, también identifican este rol y señalan que el centro procura crear un ambiente familiar para arropar al alumnado, estrechar relaciones y que se sientan como en familia, entre hermanos.

Para las y los docentes es un acto de generosidad tremendo; además, la directora es una persona con fuerza y generosa que lo da todo sin condiciones (GP-D-CA). Un personal no docente describe el accionar de ella como una hazaña épica por la tarea prioritaria que efectúa, al procurar sacar a las familias del carril de la marginalidad y buscar modificar patrones de conducta a través del estudiantado. Otra metáfora que surge en palabras del informante es la del Santo Job para señalar el grado de tolerancia y servicio de quien asume el papel de director en este tipo de centro educativo.

La directora lo que hace es intentar, solventar los problemas. Además, hace algo que para mí es una auténtica heroicidad: conseguir que estos niños tengan una opción distinta. Estos niños van por un carril que son sus familias, viven de unas ayudas públicas, y son familias marginales desde hace ocho generaciones. Por tanto, hay que sacarlos del carril para que tomen otra vía (EP-C-CA) (Rodríguez, comunicación personal, 19 de diciembre de 2019).

Igualmente, el alumnado reconoce que la directora asume el puesto del padre o la madre, valorando positivamente el carácter recto. "La directora es estricta, pero nosotros no vemos que sea así; la vemos como mejor para nosotros, porque lo transmite con mucho cariño, como si fuera nuestra madre" (GP-E-CA) (Rodríguez, comunicación personal, 19 de diciembre de 2019).

\section{El voluntario}

Se evidencia como una labor social entendida a un servicio del centro a la colectividad; al no disponer de equipos interdisciplinarios son los directores quienes asumen tareas en busca de amortiguar carencias económicas y afectivas del estudiantado que llega a los centros educativos ubicados en contextos complejos. Para los directivos del caso A, es una entrega voluntaria hacia estudiantes y familias; en esta institución evitan la cultura de la queja y la actitud de esclavitud o crucifixión. Vinculan el concepto de asistencia social con la metáfora del apostolado (EP-DIR-CA), para otros es una tarea hercúlea para llenar vacíos que dejan las desigualdades sociales y que repercuten en los resultados académicos del estudiantado, con ello del centro (identificados de difícil desempeño o centros guetos):

Esto es una función extra que hay que cumplir [...] lo vemos como una necesidad más, sabemos que es un trabajo extra [...] pero sabemos que nos va a producir un beneficio y una satisfacción [...] puede ser a nivel académico o a nivel afectivo (EPD3-CA) (Rodríguez, comunicación personal, 19 de diciembre de 2019).

Personas externas al centro y personal no docente reflexionan sobre el voluntariado, evidenciados en los proyectos que desarrollan; al ser de libre elección la aplicación depende de cuánto quiere sacrificar el director y el grupo de trabajo. Las familias describen este rol, enfatizando que la directora es una persona que vela por todos, se preocupa por todos (GP-F-CA).

Por último, se expone la metáfora del capitán de barco. La directora del Caso 3 argumenta que es un rol en el cual se necesita la colaboración de todos quienes hacen parte del centro educativo, para caminar hacia un mismo horizonte, siempre con la dirección y el liderazgo de quien ejerce la tarea directiva

\section{DiscuSIÓN DE LOS DATOS}

Las metáforas que emergen de la investigación analizan las interrelaciones entre las funciones y los roles, estructura y la cultura organizativa (Gago y San Fabián 1993; Gairín, 1995; López y Álvarez, 1999; Martínez, 2003 y Santos, 2015). Sin embargo, la mirada apunta hacia aquella lógica de acción (Manzione, 2011) que en ocasiones pasan desapercibidas, pero coadyuvan a definir con exactitud la labor del directivo, en el cómo 
organiza su tarea y por qué decide adoptar ciertos roles. Estas son acciones que se dan tras bastidores (Santos, 1994): director bombero, la madre, el mediador, vigilancia y control, el director metamorfosis. Todas ellas, develan una forma de ejercicio de la función directiva, que es la cotidianidad de vida de algunas instituciones educativas. Llevando a la reflexión que quizás las metáforas, también son conceptos que describen una realidad existente, opacada por circunstancias externas e internas de la organización escolar.

No obstante, como señaló en su momento Bronfenbrenner (1985) es difícil brindar apoyo a los individuos y sus familias sin un conocimiento del contexto primario. Un directivo puede saber más del estudiantado que del entorno en el que viven; en consecuencia, tales prácticas puedan que no se desarrollen, si lo hacen, no generen un efecto positivo (Caso B), es decir, el rol se ejerce porque las circunstancias lo exigían.

Quiere decir que, a la lista de tareas normativizadas se debe añadir otros determinados según la caracteristica de la institución y su contexto para dar voz a otras actividades directivas; y que no queden sosegadas, aunque se deba enfrentar un nuevo perfil directivo flexible y adaptativo.

El término otros, refiere porque no hay una definición exacta que logre recoger lo que se hace o debe ser, por ello que se recurren a metáforas que:

Declaran y delatan, en gran medida, los modelos de pensamiento que de otro modo no lograrían alcanzar la luz. En los registros educativos fácilmente se encuentra una serie de imágenes que forman parte del lenguaje cotidiano. Se utiliza con la misma naturalidad que cuando se recurre a otras palabras que no rememoran otra realidad diferente. (Vázquez, 2007a, p. 140).

Se aclara que estas alegorías no tienen por qué guardar relación con otras halladas en anteriores estudios, pues son constructos que recogen una realidad específica. Por ejemplo, la metáfora de madre y de asistente social, tal vez se podrían acercar a las acciones ejercidas por los directores que participaron en el estudio de Cantón y Arias (2010) que las investigadoras llamaron directores mesiánicos, salvadores, o quizás no. Es decir, que tienen entidad propia pues describieron una realidad vivida por un grupo de sujetos determinados según lo percibido por su sentido, poniendo en juego hasta la imaginación, de ahí que, se habla de una cosa para dar sentido a otra (Antonorsi, 2017).

En estos casos, se infiere que las políticas públicas no tienen gran alcance en cuanto a la satisfacción de las necesidades del estudiantado mencionadas en una investigación de Moreno (2013), cuando relaciona a la guetización escolar como una forma de exclusión social.

Algunos papeles son ejercidos, pero no aceptados como es el caso de director del Caso A, aunque lo tenía que hacer, consideraba que dificultaba el responder a los requerimientos inmediatos del alumnado; obligando a desatender las funciones sustanciales, dadas por la normativa. Lo anterior, se reflejó en un estudio de Navarro (2002); pero, el autor manifestó que los nuevos roles de un directivo exigían desarrollar nuevas destrezas y habilidades, motivando diseñar tantos perfiles como programas de formación.

\section{Conclusiones}

De acuerdo al objetivo de estudio sobre el análisis de las prácticas directivas a través del diálogo con actores claves (directivos, docentes, estudiantes, familias, entre otros) se concretaron una serie de metáforas o alegorías para conceptualizar otras actividades desarrolladas por los directivos; y que ayudan a develar con objetividad está función, destacando: el bombero o apaga fuego, la madre, rol de prevención y mediación, vigilancia y control, entre otros.

Las metáforas o alegorías expuestas no tienen nada que ver con los estilos de dirección o liderazgo que suelen adoptar algunos rectores (los tres directores tienen distintas formas de ejercer la dirección y liderazgo). Todo parece indicar que la función directiva no es algo que se desarrolla con estricto cumplimiento de la normativa, sino conlleva la puesta en práctica de otros papeles que se reflejan de acuerdo a circunstancias específicas, propias de la dinámica cambiante de los centros. 
Es decir, los distintos perfiles directivos exigen de cierta flexibilidad y adaptabilidad por la complejidad, cambiante en los centros educativos. De ahí que, una de las interrogantes que queda para despejar es ¿Los actuales directores están preparados para ser el principal agente social del cambio? Pues se evidencia que, las actuales estructuras que se enmarca la colectividad hacen que los entornos sociales sean heterogéneos, bien sea por la amalgama cultural que forman las familias o por el factor económico que demanda adecuar los perfiles directivos existentes o buscar su complementariedad.

\section{REFERENCIAS BIBLIOGRÁFICAS}

Alcaide, M. (2009). Influencia del rendimiento y autoconcepto en hombres y mujeres. Revista Electrónica de Investigación y docencia, 2, 27-44. Recuperado de https://revistaselectronicas.ujaen.es/index.php/reid/article/v iew/1105/930

Antonorsi, M. (2017). Metáforas de la organización. Recuperado de https://antonorsi.com/articulos/

Barbour, R. (2013). Los grupos de discusión en Investigación Cualitativa. Madrid: Moratta.

Bogdan, R. y Biklen, S. (2003). Qualitate research for education: an introduction to theories and methods. New York: Allyn \& Bacon.

Bolívar, A. (2018). Los estudios sobre la dirección escolar: Un panorama bibliográfico. Cuadernos de Pedagogía, 490, 116-120. Recuperado de https://bit.ly/2zJ5ISG

Bronfenbrenner, U. (1985). Contexto de Crianza del Niño. Problemas y Perspectivas. Infancia y Aprendizaje, 3, 45-55. doi: https://doi.org/10.1080/02103702.1985.10822058

Bunk, G. (1994). La transmisión de competencias en la formación y perfeccionamiento profesionales de la RFA. Revista Europea de Formación Profesional, 1, 8-14. Recuperado de https://dialnet.unirioja.es/servlet/articulo?codigo= 131116

Cantón, I., y Arias, A. (2010). Metáforas y teorías implícitas de los directores escolares. Education Siglo XXI, 28(1), 227-248. Recuperado de https://revistas.um.es/educatio/article/view/109801

Cavallín, C. (2008). Posibilidades de la metáfora en Borgués. Atenea, 498(2), 45-54. doi: http://dx.doi.org/10.4067 /S0718-04622008000200004

Díaz, C., Alfaro, B., Calderón, L., y Álvarez, N. (2010). Los Protagonistas de los Consejos Educativos Institucionales: Tensiones y Dilemas de la Participación en la Gestión de la Escuela Pública. Revista Iberoamericana sobre Calidad, Eficacia y Cambio en Educación, 8(3), 32-49. Recuperado de http://www.rinace.net/reice/numeros/arts/vol8n um3/art2.pdf

Domínguez, J. (2010). Liderazgo (Metáfora de la carpintería). Recuperado https://bit.ly/2yGtcYc

Eagleton, T. (1983). Una introducción a la teoría literaria. Estados Unidos de América: Basil Blackwell Publishers Limited, Oxford

Flick, U (2014). La gestión de la calidad en investigación cualitativa. Madrid: Ediciones Morata.

Gago, F., y San Fabián, J. S. (1993). “La dirección pedagógica en los centros escolares”. En J. Gairín y S. Antúnez (Eds.), Organización escolar: nuevas aportaciones (pp. 79-594). Madrid, España: Promociones y Publicaciones Universitarias, PPU. Recuperado de https://dialnet.unirioja.es/servlet/articulo?codigo=996881

Gairín, J. (1995). Estudio de las necesidades de formación de los equipos directivos de los centros educativos. Madrid: Ministerio de Educación, Cultura y Deporte.

Goleman, D. (2002). Inteligencia emocional. Barcelona: Kairós.

Guba, E. (1981). Criteria for Assesing the truthworthiness of naturalistic inquiries. ERIC/ECTJ Anual, 29(2), 75-91. Recuperado de https://www.infor.uva.es/ amartine/MASUP/Guba.pdf

Hirshfield, J. (2014). El arte de la metáfora. Madrid: TED - Ed.

López, J., y Álvarez, M. (1999). La evaluación del profesorado y de los equipos docentes. Madrid: Síntesis. 
Lorenzo, N. (2011). La profesionalización de la función directiva. Competencias para la dirección. Congreso FEDADI. Recuperado de https://www.slideshare.net/nlorenzo/la-profesionalizacin-de-la-funcin-directiva-competencias -para-la-direccin

Lorenzo, M. (2005). El liderazgo en las organizaciones educativas: revisión y perspectivas actuales. Revista Española de Pedagogía, 63(232), 367-388. Recuperado de https://bit.ly/2MaDliZ

Manzione, M. (2011). La dirección escolar en Argentina: Reconfiguraciones del rol en contextos inciertos. Cuadernos CEDES Campinas, 31(83), 103-125. doi: http://dx.doi.org/10.1590/S0101-32622011000100006

Martínez, J. (2003). mestres i exili. Barcelona: Edicions Universitat Barcelona.

MILENIUM 3. (2010). Diagnóstico estratégico del barrio Oliver. Servicio de gestión de conocimiento S.L. Recuperado de http://www.ebropolis.es/files/File/Documentos/diagnostico-Oliver.pdf

Moreno, Á. (2013). La guetización escolar, una nueva forma de exclusión educativa. Revista de educación, 361, 358-378. Recuperado de https://bit.ly/3euHj25

Navarro, M. (2002). Reflexiones de/para un director. Madrid: NARCEA.

Nieto, S. (2012). "Proceso general de investigación". Principios, métodos y técnicas esenciales para la investigación educativa. Madrid: Dykinson

Proyecto Educativo de Centro. (2015). Colegio Santo Domingo [Documento en papel policopiado]. Zaragoza, España.

Rodríguez, E. (2018). El ejercicio de la función directiva en contextos complejos: su profesionalización. Perspectiva Educacional, 57(3), 131-152. doi: http://dx.doi.org/10.4151/07189729-vol.57-iss.3-art.775

Sabirón, F. (2006). Métodos de investigación etnográfica en ciencias sociales. Zaragoza, España: Mira

Santos, M. A. (2015). La feromona de las manzanas o el valor educativo de la dirección. Barcelona: GRAO Ediciones.

Santos, M.A. (1994). Entre bastidores. El lado oculto de la organización escolar. Málaga, España: Aljibe.

Tejada, J. (1999). Acerca de las competencias profesionales. Herramientas, 2(57), 20-30. Recuperado de https://bit. $\mathrm{ly} / 2 \mathrm{X} 9 \mathrm{bLsO}$

Tojar. J.C. (2012). "La investigación cualitativa en educación". Principios, métodos y técnicas esenciales para la investigación educativa. Madrid: Dykinson.

Vázquez, R. (2007a). Las metáforas: Una Vía Posible para Comprender y Explicar las Organizaciones Escolares y la Dirección de Centros. REICE: Revista Iberoamericana sobre Calidad, Eficacia y Cambio en Educación, 5(3) 137-151. Recuperado de https://bit.ly/36F7yjz

Vázquez, R. (2007b). Reflexiones sobre el tiempo escolar. Revista Iberoamericana De Educación, 6(42) 1-11. doi: htt ps://doi.org/10.35362/rie4262373

\section{REFERENCIAS}

Vázquez, R. (2011). Investigar la dirección escolar con estudio de caso. Málaga- España: Aljibe.

\section{BY-NC-ND}

